\title{
GENICALLY CONTROLLED VARIABILITY OF CHROMOSOME NUMBER IN PENNISETUM HYBRIDS*
}

\author{
P. GILDENHUYS and KÄTHE BRIX \\ Deportment of Genetics, University of Notal, Pietermoritzburg, South Africa
}

Received 9.iii.64

\section{INTRODUCTION}

Crosses between annual diploid Pennisetum typhoides $(2 n=14)$ and perennial tetraploid $P$. purpureum $(2 n=28)$ yield sterile perennial triploids $(2 n=21$ ) with regular mitotic behaviour (Gildenhuys and Brix, 1961). A colchicine-induced hexaploid (amphiploid), though fertile does not cross as readily with $P$. typhoides as does the tetraploid. Moreover, the amphiploid shows intraplant variability in somatic chromosome number and when backcrossed to $P$. typhoides the progenies differ with regard to stability of somatic chromosome number. The present investigation was undertaken in an endeavour to determine the nature of (i) the high degree of incompatibility in the cross diploid $\times$ hexaploid and (ii) the differences between backcross plants in their stability of somatic chromosome number.

\section{PROCEDURE}

The procedure for inducing amphiploidy has been described before (Gildenhuys and Brix, 196r). The amphiploid of one $F_{1}$ plant was crossed onto many plants of $P$. typhoides in the two successive seasons $1960-61$ and $1961-62$. Using the latter, which is markedly protogynous, as female, emasculation is avoided and it is relatively easy to distinguish the hybrids from the selfs.

At fixed periods after pollination $(6,24,48,72,96,120$ and 144 hours) florets of $P$. typhoides which had been pollinated either with amphiploid or $P$. typhoides (control) pollen were fixed in Carnoy's $(6: 3: 1)$ fixative. These were later examined for growth of pollen tubes, embryo and endosperm development, after sectioning and staining as described by Gildenhuys and Brix (1959).

Roots from all the backcross hybrids and from the amphiploid were prefixed for $2 \frac{1}{2}$ hours in a saturated aqueous solution of $\alpha$ bromonaphthalene, stained in iron-acetocarmine fixative, boiled and squashed in carmine. Fifty late prophase-metaphase plates werc examined for each plant and the chromosome numbers were noted. Only completely intact cells in which the chromosomes were well spread out were considered.

* Read at the XIth International Congress of Genetics, The Hague, Netherlands, 2nd to 10 th September 1963 . 


\begin{tabular}{|c|c|c|c|c|c|}
\hline \multirow{27}{*}{ 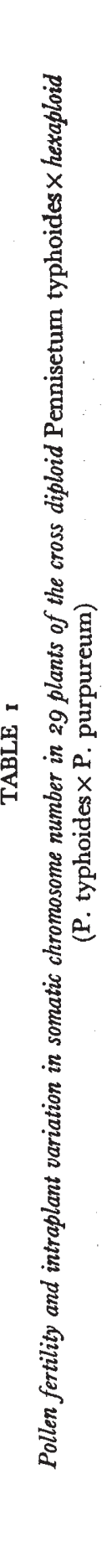 } & \multicolumn{3}{|c|}{ 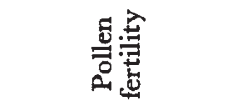 } & 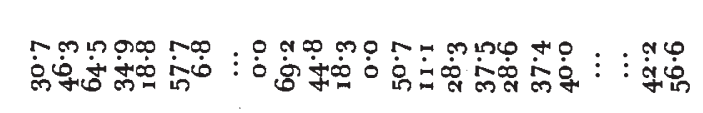 & $\stackrel{0}{i=1} \dot{0} \dot{0} \dot{0}:$ \\
\hline & & F & & $\vdots \vdots \vdots \vdots \vdots \vdots^{\text {๙ }} \vdots$ ๙ $\vdots \vdots \vdots^{\curvearrowright} \vdots \vdots \vdots \vdots \vdots \vdots \vdots \vdots \vdots \vdots \vdots$ & $\vdots \vdots \vdots \vdots \vdots$ \\
\hline & & 우 & & 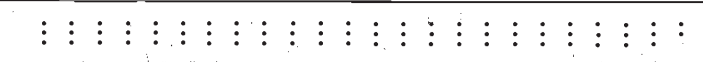 & $\vdots \vdots \vdots \vdots$ \\
\hline & & g & & 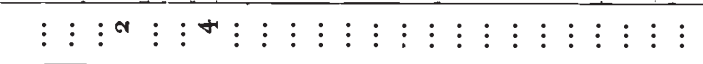 & $\vdots \vdots \vdots \vdots \vdots$ \\
\hline & & $\stackrel{m}{\infty}$ & & $\left.\vdots \vdots \vdots^{\text {ศ }} \vdots \vdots^{\text {ศ๐ }} \vdots \vdots \vdots+\right)^{\text {๙ }} \vdots \vdots \vdots \vdots \vdots \vdots \vdots \vdots$ & $\vdots \vdots \vdots \vdots \vdots$ \\
\hline & & $\hat{m}$ & & 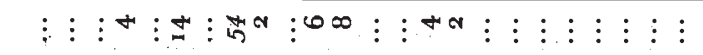 & $\vdots \vdots \vdots \vdots \vdots$ \\
\hline & & $\varphi_{m}$ & & 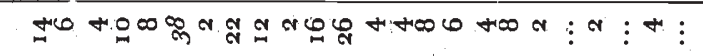 & $\vdots \vdots \vdots \vdots \vdots$ \\
\hline & & 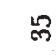 & & 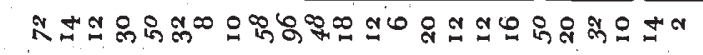 & $\vdots \vdots \vdots \vdots \vdots$ \\
\hline & & ले & & 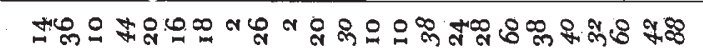 & $\vdots \vdots \vdots \vdots \vdots$ \\
\hline & & ๓ & & : & $\vdots \vdots \vdots \vdots \vdots$ \\
\hline & & के & & $\vdots \infty \infty$ ๙ & $\vdots \vdots \vdots \vdots \vdots$ \\
\hline & & $\bar{m}$ & & $\vdots \vdots$ 워 & $\vdots \vdots \vdots \vdots \vdots$ \\
\hline & & 㝏 & 党 & 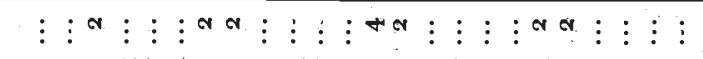 & $\vdots \vdots \vdots \vdots \vdots$ \\
\hline & है & के & 良 & 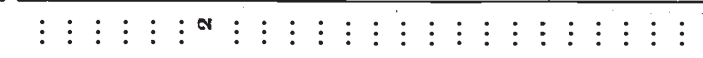 & or $\vdots \vdots \vdots$ \\
\hline & घूँ & $\stackrel{\infty}{\sim}$ & 造 & $\vdots \vdots \vdots \vdots \vdots \quad \vdots \quad \vdots \quad \vdots \quad \vdots \quad \vdots \quad \vdots \quad \vdots \quad \vdots \quad \vdots \quad \vdots \quad \vdots \quad \vdots \quad \vdots \quad \vdots \quad \vdots \quad \vdots \quad \vdots$ & फें山े $\vdots \vdots$ \\
\hline & 莬 & $\hat{a}$ & & $\vdots \quad \vdots \quad \vdots \quad \vdots \quad \vdots \quad \vdots \quad \vdots \quad \vdots \quad \vdots \quad \vdots \quad \vdots \quad \vdots \quad \vdots \quad \vdots \quad \vdots \quad \vdots \quad \vdots \quad \vdots \quad \vdots \quad \vdots \quad \vdots \quad \vdots$ & 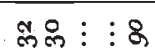 \\
\hline & 总 & \% & & 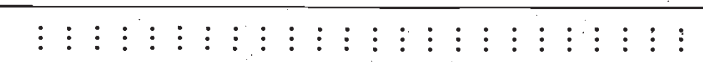 & $0 \cong: \vdots:$ \\
\hline & & $\stackrel{w}{a}$ & & 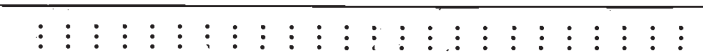 & r⿻ $\vdots \vdots \vdots$ \\
\hline & & A & & 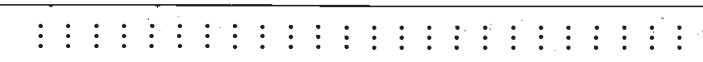 & $\vdots$ oce $\vdots$ o \\
\hline & & 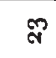 & & 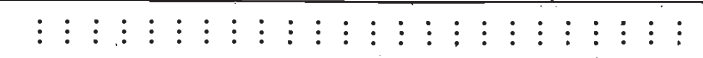 & $\vdots \vdots$ 少 $\vdots \vdots$ \\
\hline & & สี & & 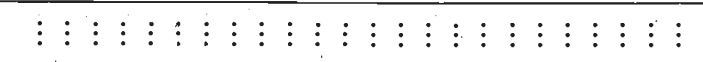 & $\vdots$ ศ พิษ \\
\hline & & $\ddot{4}$ & & 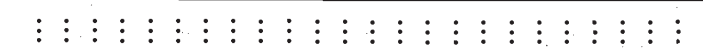 & $\vdots \vdots \vdots \infty$ \\
\hline & & \&े & & $\vdots \vdots \vdots \vdots \vdots \vdots \vdots \vdots \vdots \vdots \vdots \vdots \vdots \vdots \vdots \vdots \vdots \vdots \vdots \vdots \vdots \vdots \vdots \vdots \vdots \vdots$ : & $\vdots \vdots \vdots \vdots$ \\
\hline & & 9 & & 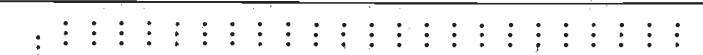 & $\vdots \vdots \vdots \vdots \vdots$ \\
\hline & & $\infty$ & & 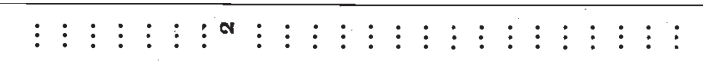 & $\vdots{ }^{\text {ศ }} \vdots \vdots \vdots$ \\
\hline & & $\approx$ & & 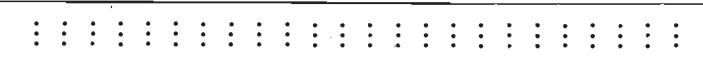 & $\vdots \vdots \vdots^{\text {ศ }} \vdots$ \\
\hline & & $\begin{array}{l}\dot{0} \\
z \\
\text { 䓌 } \\
\dot{a}\end{array}$ & & ーツ+1 & No $9 \%$ \\
\hline
\end{tabular}


The fertility of all plants which flowered was estimated by counting out of 400 the number of full pollen grains which stained well in aceto-carmine.

\section{OBSERVATIONS}

From the crosses made during the season I960-6r, 897 seeds were obtained. Plants raised from these yielded only two hybrids. In the subsequent season 27 hybrids were obtained from 6853 seeds. All the hybrids are perennial.

Pollen fertility in the amphiploid was estimated at $68 \cdot \mathrm{I}$ per cent. Pollen tube growth and fertilisation appeared to be normal, both for the crosses and the controls. Fertilisation took place approximately 6 hours after pollination. In the controls, the embryo usually began its development by the time the endosperm had reached the $16-32$ nucleate stage (24-36 hours after pollination). After this, development of the seed continued in the normal way. Whilst the hybrid endosperm followed a similar pattern of development as the controls, at least up to the time it became cellular, this was not the case with the hybrid embryos. Of 97 ovules which were fixed 48 hours and later after pollination only ig (19.6 per cent.) had embryos which were apparently developing normally, whilst 9 had pro-embryos in the 2-5 nucleate stage. The vast majority (69) showed no signs of a developing embryo. It appears then as though the initial breakdown in seed development takes place in the developing embryo and not in the endosperm, although the latter ceases to develop by the time it becomes cellular or just before then.

Chromosome number in the amphiploid varied from 36 to 49 , differences in number occurring even between cells of the same root. The most frequent number was $2 n=42$. Similarly, the backcross plants showed intraplant variation in chromosome number (table I). The ranges and variability in chromosome numbers differ very markedly between plants. Thus, for instance, the number for plant No. I3 is virtually constant, whilst plant No. Io shows marked instability (table I). If the number which occurs most frequently in each plant is taken as its true number (figures italicised in table $\mathrm{I}$ ) it can be seen that only two plants have the expected $2 n=28$ chromosomes, whilst three plants had less $(2 n=2 \mathrm{I}, 23$ and 27). The remaining 24 plants possibly arose from unreduced egg cells in $P$. typhoides, as has occurred in the cross $P$. typhoides $\times P$. squamulatum (Patil et al., I96I) and they comprise the following:- $2 n=32$ (I plant), $33(6), 34(8), 34$ and 35 (I), 35 (6), 36 (I) and $2 n=37$ (I plant). The gametic output of the amphiploid followed, therefore, the pattern expected from an examination of its meiosis, which shows irregularity causing chromosome number to vary at telophase II between $n=\mathbf{I} 2$ and $n=23$ (Gildenhuys and Brix, unpublished). The ranges and frequencies of different somatic chromosome numbers for certain selected plants are shown in fig. $\mathbf{I}$. 
Most of the backcrosses (25) flowered before the end of the season and the fertility of their pollen ranged from 0.0 to 69.2 per cent. (table I). In fig. 2, the fertility of these plants is plotted against their variability in somatic chromosome number (standard deviations). Whilst there appears to be generally some association between somatic

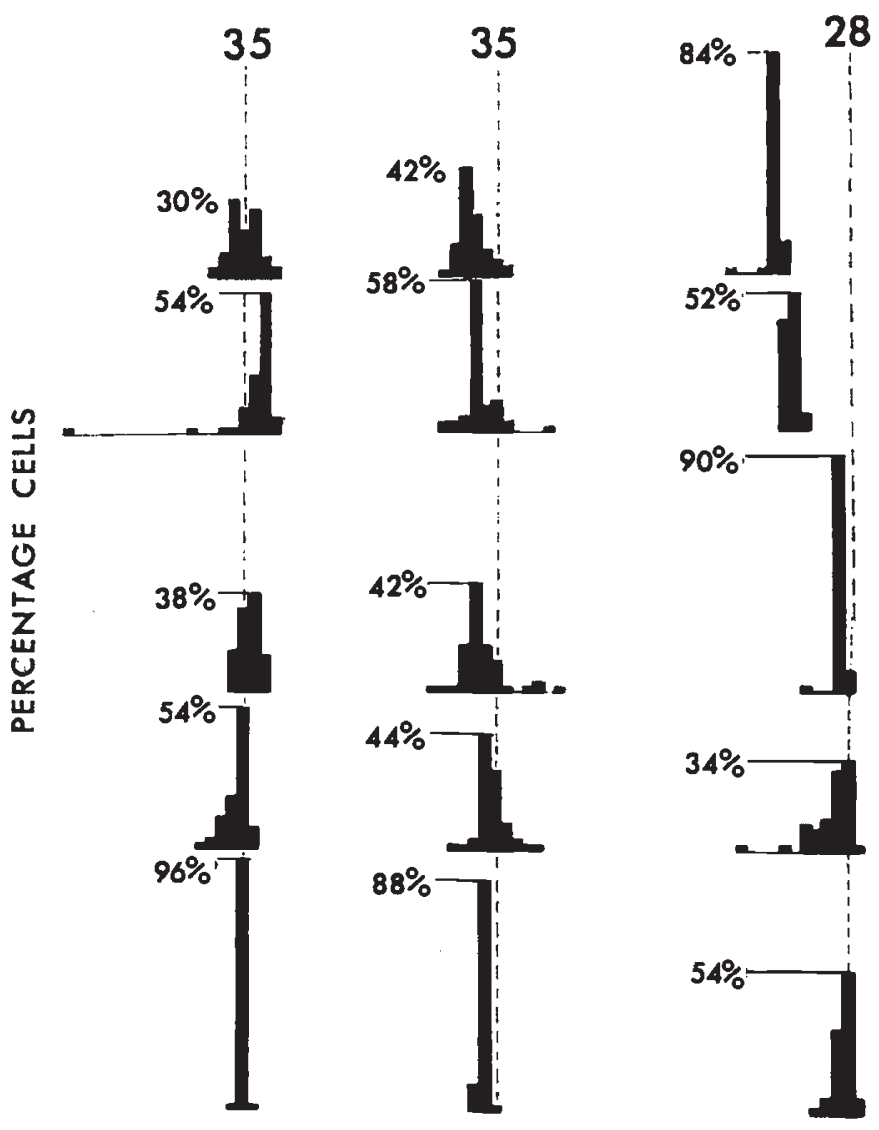

CHROMOSOME NUMBER

Fro. 1.-Frequency distributions of different chromosome complements per cell in root tips of 15 plants of the cross $P$. typhoides $\times$ hexaploid (P. typhoides $\times P$. purpureum).

stability and pollen fertility, as is the case with somatic stability and seed set in wheat $\times$ rye hybrids (Vettel, 1960) and in $P$. dubium (Gildenhuys, 1958), this is not so for all plants. The most stable plant (No. I3), also shows the highest fertility, but certain fertile plants (e.g. Nos. 4 and 18) show instability whilst a fairly stable plant (No. I) shows only moderate fertility. However, the trend is apparent in that virtually all plants of very low fertility are also unstable in their chromosome number, the only exceptions being Nos. I 9 and 20 which are sterile and fairly stable. Their sterility is possibly due to their 


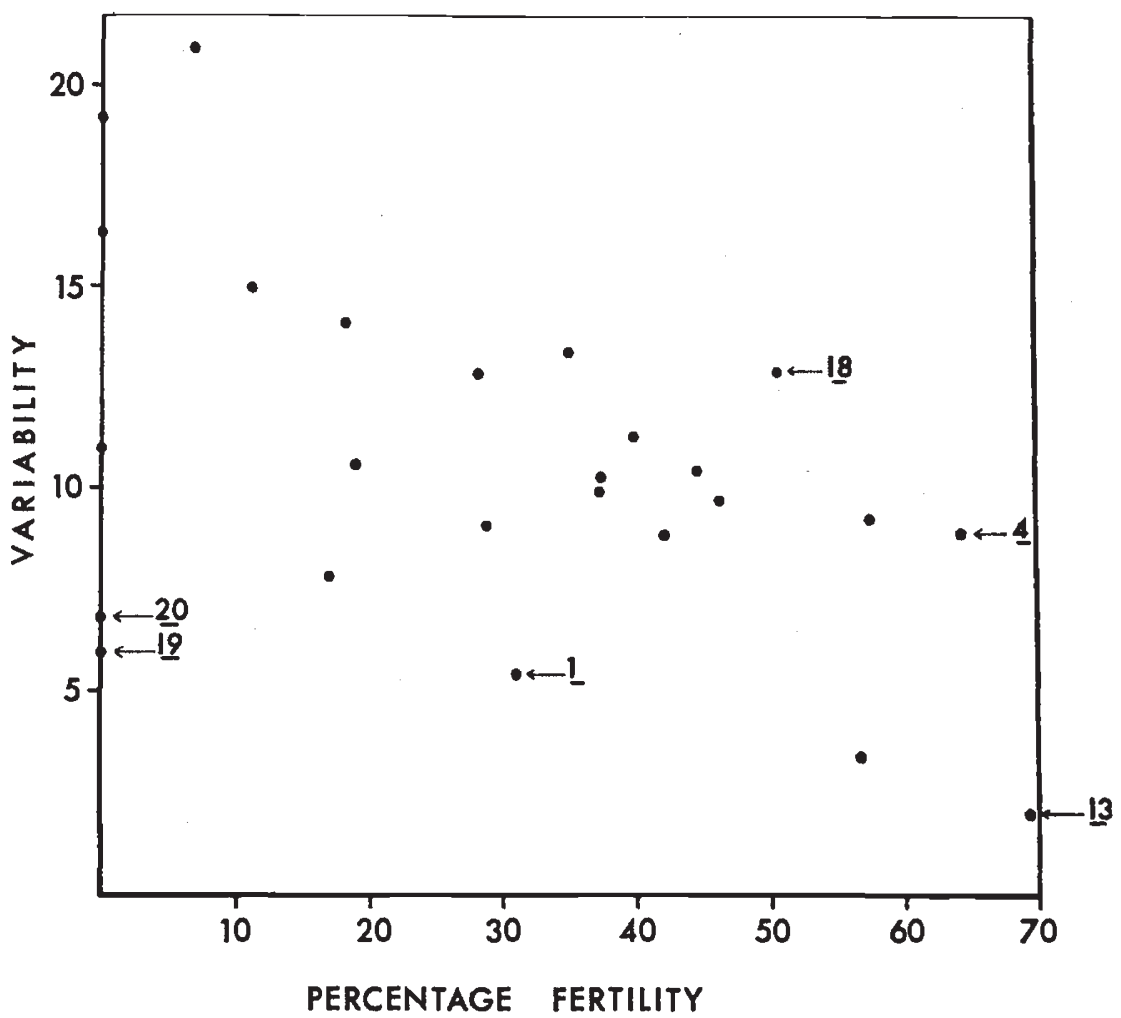

Fig. 2.- Scatter diagram of intraplant variability in chromosome number and pollen fertility of 25 plants of the cross $P$. typhoides $\times$ hexaploid $(P$. typhoides $\times P$. purpureum).

triploid nature $(2 n=23$ and $2 \mathrm{I}$ respectively-table I). Deviations from the association could of course be explained on other cytogenetic grounds.

\section{DISCUSSION \\ (i) Incompatibility}

Krishnaswamy and Raman (1956) found no difficulty in obtaining hybrids between diploid $P$. typhoides and hexaploid (amphiploid$P$. typhoides $\times P$. purpureum) whichever way they crossed them. In the hexaploid at present under consideration anthesis took place late in the season when the nights were cold. Such conditions are known to be unfavourable for obtaining hybrid seed (Reusch, I959a, Younger, 1961). However, since the initial cross diploid $P$. typhoides $\times$ tetraploid $P$. puerpureum, made under similar conditions, yielded an abundance of hybrids, it appears as though causes additional to unfavourable environment are responsible for the high degree of incompatibility encountered in the present investigation.

An examination of the chromosome numbers of the hybrids obtained in the two seasons shows that the two hybrids obtained during the first season (Nos. I9 and 20-table I) both had less than 
the expected $2 n=28$ chromosomes. During the second season, when seed of $P$. typhoides from a different source was used, only 3 of the 27 hybrids arose from reduced eggs. The frequency with which unreduced eggs occurred in this population is of course unknown, but from the frequency of hybrids obtained from them compared with that of hybrids arising from the more frequent and normal haploidisation process, it would appear that pollen from the hexaploid is more compatible with diploid than with haploid eggs. This cannot be explained on a basis of ratio of chromosome number in embryo, endosperm and maternal tissue per se as has been done in other crosses (reviewed by Oehler, 1958). In this instance the ratios of chromosome numbers in the embryo, endosperm (assumed to be pentaploid in all backcrosses) and maternal tissue of the different crosses and their compatibility are, respectively, as follows:-

diploid $\times$ tetraploid- $3: 4: 2-$ compatible

diploid $\times$ hexaploid-4:5:2-low compatibility

diploid (unreduced egg) $\times$ hexaploid-5:5:2-compatible.

The incompatibility can also not be explained in terms of chromosome number in the ratios embryo:endosperm or endosperm:maternal tissue (cf. Reusch, r $959 b$ and others) even when the possible genomic constitution, postulated by Krishnaswamy and Raman (1956), is taken into account. It appears rather that in this material, judging by the chromosome numbers of the backcrosses, compatibility is enhanced when the egg is unreduced or the pollen contains less than the haploid set, and that the incompatibility probably resides in the embryo alone, independently of the other tissues. The observed normal development of the endosperm and the retarded and sometimes abortive development of the embryo appear to substantiate this conclusion. Such a situation occurs also in interspecific crosses in Nicotania, but in the latter a I : I ratio of maternal:paternal chromosomes causes the greatest embryo abortion and deviations therefrom are more compatible (Moav and Cameron, r96r), whereas in the crosses under consideration ratios of $I: 2$ and $2: 3$ are more compatible than a $I: 3$ ratio.

\section{(ii) Intraplant aneuploidy}

The intraplant aneuploidy exhibited by these backcrosses did not occur in similar backcrosses involving the same species made elsewhere (Krishnaswamy and Raman, 1956). A growing volume of literature now exists regarding naturally occurring intraplant variation in chromosome number (reviewed by Gildenhuys and Brix, I958; Nielsen I96I and others). In the main this abnormality has been attributed, in various organisms, to spindle abnormalities which are either (i) under genic control (Sachs, 1952; Gildenhuys and Brix, I958, I96I) or (ii) the result of the "duality" of the nucleus (in hybrids) in a foreign cytoplasm, with resultant unbalanced enzyme and amino-acid synthesis (Pohlendt, r958; Nielsen, I96r). 
Whilst no spindle abnormalities were observed in the amphiploid or in the backcrosses under discussion, their existence cannot be ruled out a priori, particularly in view of the fact that instability is not as marked as, for instance, in the irregular polyploid $P$. dubium (Gildenhuys and Brix, I958) or in the putative amphiploid $P$. typhoides $\times$ $P$. dubium (Gildenhuys and Brix, I96I), so that such abnormalities would not be so readily detectable. Whatever the mechanical cause of this type of aneuploidy, its genetic basis, in Pennisetum at least, is now becoming clearer. Whereas the existence of chromosome mosaics in experimental amphiploids in the Triticine and their absence in the parents and the $F_{1}$ was attributed to genes but was not dependent on the magnitude of chromosome number (Sachs, I952), this is not so in Pennisetum. It has already been shown that $\mathrm{F}_{1}$ interspecific hybrids in Pennisetum with the same cytoplasm and which differ in their triploid content only in the 14 chromosomes received through the pollen do not show mosaicism, but when amphiploidy is induced they respond in a markedly different manner, revealing that mosaics result only when the genes controlling them are present in higher dosage (Gildenhuys and Brix, I96I). In the present amphiploid, due to its polyploid constitution, genomic content $(A A A A B B)$ and meiotic behaviour (Krishnaswamy and Raman, I954, I 956), it is possible to recover in the backcrosses more homologues and/or non-homologues carrying the genes responsible for aneuploidy than in the diploid or tetraploid parents or their triploid hybrid. Variability in recovery is reflected in the backcross progenies, which differ significantly from plant to plant in the expression of mosaicism and hence show segregation for the chromosomes and genes present in the amphiploid and its parent(s). If the cytoplasm plays any role at all (cf. Nielsen, I96I) it probably merely acts as a barrier to the expression of these genes in lower dosage. This would ensure the survival of the diploid and tetraploid parents, as instability could lead to their elimination through competition in nature.

If it is assumed that instability in chromosome number interferes with the normal development of the embryo and/or endosperm, then the cause for instability is in fact also the cause for incompatibility (sterility). That such a situation could occur in the embryos of the crosses under consideration can be explained by a simple genetic model. Assume the presence of only two pairs of independent genes $E$ and $F$ in the $A$ genome. Assume also that their recessive alleles $e$ and $f$, each responsible for instability when in higher dosage whether in a foreign cytoplasm or not, to be absent in say Pennisetum purpureum material used by other workers but present in ours. Assume further that these recessives show additive effects when not masked by too many dominant alleles. Thus genotype $E E e^{\prime}-F f^{\prime} f^{\prime}$ would show higher instability than $E E E e^{\prime} F F f^{\prime} f^{\prime}$. 'The crosses under consideration are then constituted as follows: $-P$. typhoides $(E E F F) \times P$. purpureum $\left(E e^{\prime} F f^{\prime}\right)$. Supposing further the double heterozygote to be the $\mathrm{F}_{1}$ 
used in our material, then the constitution of the amphiploid would be $E E e^{\prime} e^{\prime} F F f^{\prime} f^{\prime}$, which is unstable because of the higher dosage $e^{\prime} e^{\prime}$ and also $f^{\prime} f^{\prime}$. The gametes and zygotes in the back-crosses would be as follows:-

TABLE 2

\begin{tabular}{|c|c|c|}
\hline \multirow{3}{*}{$\begin{array}{l}\text { Amphiploid } \\
\text { gametes }\end{array}$} & \multicolumn{2}{|c|}{ P. typhoides gametes } \\
\hline & Reduced egg & Unreduced egg \\
\hline & $E F$ & $E E F F$ \\
\hline $\begin{array}{l}E E F F \\
E E F f^{\prime} \\
E E f^{\prime} f^{\prime} \\
E e^{\prime} F F \\
E e^{\prime} F f^{\prime} \\
E e^{\prime} f^{\prime} f^{\prime} \\
e^{\prime} e^{\prime} F F \\
e^{\prime} e^{\prime} F f^{\prime} \\
e^{\prime} e^{\prime} f^{\prime} f^{\prime}\end{array}$ & 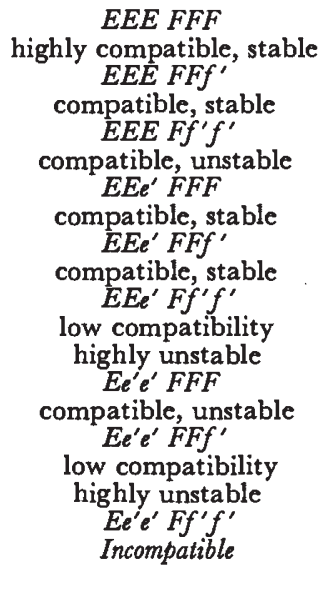 & $\begin{array}{c}E E E E F F F F \\
\text { highly compatible, stable } \\
E E E E F F F f \\
\text { highly compatible, stable } \\
E E E E F F f^{\prime} f^{\prime} \\
\text { compatible, unstable } \\
E E E e^{\prime} F F F F \\
\text { highly compatible, stable } \\
E E E e^{\prime} F F F f^{\prime} \\
\text { compatible, stable } \\
E E E e^{\prime} F F f^{\prime} f^{\prime} \\
\text { compatible, unstable } \\
E E e^{\prime} e^{\prime} F F F F \\
\text { compatible, unstable } \\
E E e^{\prime} e^{\prime} F F F f^{\prime} \\
\text { compatible, unstable } \\
E E e^{\prime} e^{\prime} F F f^{\prime} f^{\prime} \\
\text { low compatibility, } \\
\text { highly unstable }\end{array}$ \\
\hline
\end{tabular}

Gametes will be compatible if the resultant zygotes have only dominant genes or not more than one recessive allele of each gene and the zygotes will be stable. Now, in crosses with reduced eggs the amphiploid gametes with three recessive alleles show low compatibility and the resultant zygotes are highly unstable. The combination four recessive and two dominant alleles is incompatible. In crosses with unreduced eggs on the other hand, the zygotes have always two extra dominant alleles to counteract the effect of the recessives. Thus an amphiploid gamete with four recessive alleles, which is incompatible with a reduced egg, will still be compatible with an unreduced egg but will produce a highly unstable zygote with the latter.

\section{SUMMARY}

I. Hybrids between diploid Pennisetum typhoides $(2 n=14)$ and tetraploid $P$. purpureum $(2 n=28$ are mitotically stable triploids and are sterile.

2. A colchicine-induced hexaploid (amphiploid) is fertile but shows 
instability in somatic chromosome number, even in cells of the same root $(2 n=36$ to 49 with $2 n=42$ occurring most frequently).

3. When the amphiploid was used as pollen parent in backcrosses to $P$. typhoides a high degree of incompatibility was encountered and only $3 \mathrm{I}$ offspring was obtained. Of these only four had the expected $2 n$ number of 28 or less. The remainder had somatic numbers in the region of $2 n=35$ and arose from unreduced egg cells in $P$. typhoides.

4. All the backcross progenies also showed intraplant instability in chromosome number but the variability and range of chromosome numbers differ significantly from plant to plant, with some association between instability and pollen sterility.

5. Incompatibility (embryo abortion) is suggested to be the result of intraplant aneuploidy and hence an unbalance in the embryo itself rather than the result of an altered relationship in chromosome number between embryo, endosperm and material tissues.

6. It is concluded that intraplant variability in chromosome number is controlled by genes which express themselves only when present in higher dosage, as has been demonstrated in the putative amphiploid of the cross between $P$. typhoides and the mitotically unstable $P$. dubium.

The situation in our material need not of course be as simple as this, but the model affords a basis for explaining the differences not only between our backcross plants but also why the cross haploid egg $\times$ hexaploid is less successful than diploid egg $\times$ hexaploid. It also explains the differences between our own observations and those of Krishnaswamy and Raman (1956) who possibly did not have these recessives in their material and therefore experienced no difficulty in obtaining backcross hybrids and also found no intraplant aneuploidy.

\section{REFERENCES}

GILdenhuys, P. J. 1958. A cytogenetic study in two Pennisetum species and their hybrid. Ph.D. Thesis, University of Natal.

GILDENHUYs, P., AND BRIX, K. 1958. Cytological abnormalities in Pennisetum dubium. Heredity, I2, 44I-452.

gildenhuys, P. J., AND Brix, x. 1959. Apomixis in Pennisetum dubium. S.A.f. Agric. Sci., 2, 231-245.

GILDENhUYs, P., AND BRIX, x. 1961. Genic control of aneuploidy in Pennisetum. Heredity, $x 6,35^{8-363 .}$

KRIShNASWAMY, N., AND RAMAN, v. s. 1954. Studies on the interspecific hybrid of Pennisetum typhoides $\times P$. purpureum. III. The cytogenetics of the colchicine induced amphidiploid. Genetica, 27, 253-272.

KRISHNASWAMY, N., AND RAMAN, v. S. 1956. Studies on the interspecific hybrid of Pennisetum typhoides $\times P$. purpureum. IV. The cytogenetics of the allotetraploids. Genetica, $28,36 \mathrm{I}-488$.

MOAV, R., AND CAMERON, D. R. 1961. Chromosome complement dosage in relation to seed development of species hybrids in Nicotiana. Bot. Gaz., 123, 70-77.

nielsen, E. L. 1961. Cytology and fertility of Agroelymus turneri. Cytologia, 26, I37-I 54 .

oEHLER, E. 1958. Art- und Gattungskreuzung. Handbuch der Pflanzenzüchtung, 563-6ri. Paul Parey, Berlin. 
PATIL, B. D., hARDAS, M. W., AND JOSHI, A. B. I96I. Auto-alloploid nature of Pennisetum squamulatum. Nature, $189,419-420$.

POHLENDT, G. I958. Variabilität der Chromosomenzahlen und andere Kernpathologien in Aegylops truncialis $\times$ Triticum aestivum Bastarden. Zeitschr. $f$. Vererbungsl., 89, $170-188$.

REUSGH, J. D. H. I 959 a. Note on the nature of the effect of the environment on seed-viability in interspecific hybrids. S.A.7. Agric. Sci., 2, 573-574.

REUSCH, J. D. H. I959 $b$. The nature of the genetic differentiation between Lolium perenne and Festuca pratensis. S.A.7. Agric. Sci., 2, 271-283.

sAcHs, L. 1952. Chromosome mosaics in experimental amphiploids in the Triticinae. Heredity, 6, I57-I 70.

VETTEL, F. K. I96o. Mutationsversuche an Weizen-Roggenbastarden (Triticale). II. Zytologische Untersuchungen und Fertilitätsbestimmungen an Triticale Rimpau und einigen Mutanten. Der Züchter, 30, I81-I9o.

younger, V. B. I961. Low temperature induced male sterility in male-fertile Pennisetum clandestinum. Science, $133,577-578$. 